\title{
Contribuciones al estudio de Identidades e Identificaciones precarias en Chile
}

\author{
Dasten Julián Vejar \\ Universidad de la Frontera, Temuco, Chile. Becario Conicyt. 2010 - 2014. \\ Email: dasten@gmail.com
}

\begin{abstract}
Resumen: En este artículo $^{1}$ se realiza un acercamiento conceptual a las nuevas formas de identificación fragmentaria y precaria que emergen de/en el trabajo y el no-trabajo, a partir de la descomposición y regeneración de las lógicas laborales de disciplinamiento. Desarrollamos una aproximación general al caso de Chile, presentando una serie de anotaciones que ayudan a entender las nuevas subjetividades que se encuentran relacionadas a los fenómenos de precariedad y flexibilidad laboral.

Palabras clave: identificación, identidad, subjetividad, precariedad, flexibilidad, trabajo.
\end{abstract}

\section{Contributions to the study of Identifications and precarious Identities in Chile}

\begin{abstract}
This article provides a discussion of new forms of fragmentary and precarious identification, emerging from/at work and non-work, from the decomposition and the regeneration of disciplining labor logics. We develop a general approach to the Chilean case, presenting a series of notes than help to understand the new subjectivities that are related to the phenomena of labor precariousness and labor flexibility.
\end{abstract} work.

Key words: Identification, identity, subjectivity, precariousness, flexibility,

\section{Contribuições para o estudo das identidades e Identificações precárias no Chile}

Resumo: Este artigo apresenta uma abordagem conceitual para novas formas de identificação fragmentária e precária emergindo do/no trabalho e nãotrabalho, a partir da decomposição e regeneração da lógica industrial da disciplinamento. Desenvolvemos uma abordagem geral para o caso do Chile, apresentando uma série de notas que ajudam a entender as novas subjetividades que estão relacionadas com os fenómenos de precariedade do trabalho e flexibilidade laboral.

Palavras-chave: identificação, identidade, subjetividade, precariedade, flexibilidade, trabalho. 


\section{Introducción}

Los cambios sucedidos en la constante dinámica de acumulación del capital muestran sorprendentes efectos, a la hora de evaluar los impactos en el trabajo y el empleo. De hecho las transformaciones sufridas en el mundo del trabajo en las economías centralizadas e industriales a partir de las década de los 70 y 80 (Boyer 2007), han significado procesos de readaptación y reestructuración de las prácticas en el mundo del trabajo en las sociedades capitalistas periféricas (Arceo 2005), lo cual ha involucrado un cambio a nivel internacional de los procesos de coordinación, comunicación, organización y producción a nivel mundial.

En el caso de América Latina, el desarrollo y emergencia de paradigmas productivos en la década de los 80 y 90 (De la Garza \& Neffa 2010), estuvo marcado por: a) el proceso de reestructuración y modernización productiva, b) la instalación de un régimen social de acumulación disciplinario (Baker \& Gill 2003), y c) la inserción dentro de la matriz neoliberal y trasnacional de acumulación (Harvey 2007). Esta misma dinámica, conjuntamente, ha dado paso a la construcción de nuevos procesos de reorganización de la sociedad, a un nuevo modo de producir la vida y de comprender las relaciones inter-subjetivas.

Es posible así identificar un proceso de cambio y metamorfosis en las relaciones sociales, con un proceso dialéctico de emergencia/descomposición de nuevas subjetividades e identidad(es) en el mundo del trabajo. Este contexto, fue acompañado de la pérdida de certezas, la difuminación de verdades y valores unívocos, la percepción nítida de un decisivo descentramiento del sujeto, de la diversidad de los mundos de la vida (Arfuch 2005: 22), asociado a los conceptos, en sociología del trabajo, de incertidumbre, inseguridad, vulnerabilidad, es decir, las distintas vertientes de la precarización. Esta fragmentación de la conformación de sentido, en el plano de las identidades y las subjetividades, aportó a una revalorización de los pequeños relatos, a un desplazamiento del punto de mira omnisciente y ordenador en beneficio de la pluralidad (Ibid: 22).

Estas mutaciones en el plano del orden simbólico del trabajo, implicó el desafío de dar cuenta de los cambios específicos en la subjetivación de la fuerza de trabajo, en su relación entre subjetividad, cultura y estructura (De la Garza 2001), que integrándose a los nuevos paradigmas productivos, las nuevas condiciones de producción, su dinámica y cambio, sus lógicas internas y externas de (des)validación, encuentran nuevas formas de identificación, que estás atravesadas por el fenómeno de la transición, desde una precariedad marginal, hacia una precariedad discriminatoria (Dörre. 2009: 84)².

Estas transformaciones se hicieron latentes en espacios que trasgredían el espacio del trabajo, y amenazan/reformulaban las formas de reproducción de la cotidianidad y la misma existencia. Este fenómeno estaba articulado, como eje, con la profundidad de las metamorfosis que atravesaba el mundo del trabajo (Antúnez 2003), en referencia a los cambios en la 
sociedad salarial a través de la reestructuración productiva neoliberal. A partir de ello, un gran contingente de trabajadores y trabajadoras se encontraron frente a cambios difíciles en su lugar de trabajo, como la flexibilización laboral, la fragmentación de las unidades productivas, la inseguridad del empleo, el trabajo temporal, la subcontratación, las jornadas laborales extendidas, la mecanización, etc. (Cruces \& Ham 2010). En el marco de las relaciones laborales, este fenómeno abrió un espacio a la ampliación del sujeto laboral, con la manifestación de formas cada vez más precarias y flexibles de trabajo, nuevos sectores productivos y demandas de cualificaciones en el marco del proceso de transnacionalización del capital, etc., lo cual reconfiguró definitivamente la cartografía del trabajo en América Latina. Siendo este elemento parte de una nueva reconstrucción disciplinaria del trabajo y del trabajador/a, por medio de la emergencia de nuevos dispositivos disciplinares en el trabajo (Julián 2012).

Es frente y desde este panorama que pretendemos, desde la tesis de la centralidad del (no) trabajo como categoría sociológica y social, en la dinámica de rearticulación de identidad, y la crisis de una cultura laboral (y de las formas de dominación), exponer la relación polisémica y polimorfa que asume el trabajo hoy en día en su concreción, con las fracturas que exhiben la pérdida del significado social de la subordinación sumisa (Buroway 1979), comprendiendo esto como un fenómeno emergente en la realidad social, que integra una dimensión identitaria particular, en el proceso social de (re)producción de la realidad, lo cual llamamos aquí identidades precarias subalternas.

Este artículo presenta en su primera sección un debate acerca del acercamiento de las categorías de cultura, identidad e Identificación, como fenómenos dialécticos y contradictorios, en un escenario de alta fragmentación, dinámico e inestable, generando algunos acercamientos desde el proceso de identificación lacaniana, a la comprensión del sujeto de identidad, en un escenario de desgaste del significante en la cultura. En la segunda sección se analiza la relación entre los procesos de identificación y las transformaciones en el (no) trabajo, en las vertientes de la precarización, como nuevas formas constituyentes productoras de subjetividad en el trabajo. En la tercera sección presentamos una serie de anotaciones con respecto a los procesos de crisis, irrupciones de subjetividades precarias en Chile, dando cuenta del panorama del empleo precario, y su consolidación temporal. Por último se presentan las conclusiones del trabajo, referidas a la temática de la tensión entre la fragmentación y reorganización colectiva.

\section{Debates sobre Identidad(es) e Identificación.}

Desde 1960, la palabra cultura ha girado sobre su propio eje y ha empezado a significar la afirmación de identidades específicas nacionales, étnicas, sexuales, regionales en vez de su superación. Como todas esas identidades se consideraban a sí mismas reprimidas, alteridades y subordinadas, se reabrió un campo de batalla en la significación de la cultura entendida 
ésta como un campo clausurado, homogéneo y universal de valores y prácticas a partir de la crítica de las llamadas culturas, subalternas o marginales (Spivak 2003), los cuales representaban sujetos y subjetividades que habían sido barradas, desplazadas y castradas por el patrón cultural dominante. En este giro político, la cultura pasó a convertirse en una crítica que hace una forma periférica de vida a una forma de vida dominante o mayoritaria (Eagleton 2001: 72) ${ }^{3}$.

Si bien los significados y modelos dados a la cultura son abundantes $^{4}$, hoy en día, la deconstrucción muestra como toda situación, inclusive la re-significación de la cultura en su sentido marginal, está abocada a violar su propia lógica justamente cuando más intenta adherirse a ella, y por lo tanto, se podría considerarse como otra expresión de esta noción tradicional de crítica inmanente (Eagleton 40-41). Por ello la cultura más bien tiende a aparecer como un fenómeno contradictorio que implica un acelerado y progresivo desgaste de su coherencia interna y externa de las redes de sentido significantes que les son propias. Así pareciera más bien que nos encontráramos con una red estructurada y diferenciada de significantes, los cuales por medio de espacios, prácticas y lenguajes exhiben la contradicción y tensión de las estrategias de (re)producción, como modelos de construcción de sentidos.

A la vez los modelos de construcción de sentidos sólo pueden ser entendidos como procesos de producción y acumulación de significados presentes en la cultura, los cuales se encuentran embebidos de poder (Retamozzo 2005: 12$)^{5}$, y es en éstas relaciones, donde se encadenan fenómenos de rápida y demarcada polarización. La desigualdad social y la heterogeneidad de las estructuras/instituciones de la reproducción social, van definiendo las características de los procesos y espacios de socialización, interacción y comunicación, lo que instala marcas y prácticas sociales, en las cuales la transmisión y generación de sentidos va gestándose, perneándose y renovando sus antiguas nociones, significados y simbolizaciones en un permanente flujo de adaptabilidad y llenado. Por otra parte, la forma que asume el capital como abstracción que ha llegado al máximo de su despersonalización, siguiendo su lógica acumulativa independientemente de los sujetos sociales en los que se encarna (De la Garza. 2001b: 22), va reordenando las configuraciones subjetivas con respecto al trabajo, la vida y la identidad, y las somete a una constante dinámica de reactualización de la relación de subordinación y poder.

Si esta afirmación es real, debemos entender el presente como una crisis de la cultura, en su sentido normativo, estático y/o como sustrato mono-causal y monolítico que prefigura idealmente una sociedad, y en cuanto orden simbólico instituyente de lo social (Castoriadis 1993), ya que el capital dinamiza, absorbe y reorganiza los sentidos propios de las estructuras tradicionales y los remodela (negociando) en función del proceso de acumulación, a la vez que produce una actualización en el campo de las relaciones de poder, la generación de nuevas alteridades y sujetos subalternos, con la condición negativa y contradictoria de su constitución. 
A la vez, la cultura, en su descomposición y erosión permanente, en su constante contradicción y en su intrínseco malestar identificatorio, reformula, en un sentido lacaniano, las relaciones transindividuales de conformación, producción y nacimiento de los sujetos. Lacan planteaba el concepto de Discurso del Otro, como respuesta a éste orden simbólico que articulaba el sistema de convenciones significantes que componen la mítica del inconsciente y que marca al individuo prefigurado, su ubicación desde el nacimiento (Vallejos 1987: 107). Desde allí, ya se concentra una relación contradictoria en la posición del sujeto, en referencia a la matriz de simbolización, ya que el individuo que se encuentra siempre ante él con un lenguaje ya constituido y que, si carga con un sentido $<<$ privado $>>$ tal palabra, tal expresión, no lo hace con una libertad ilimitada, sino que debe apropiarse de algo que se encuentra ahí (Castoriadis 1993: 135). En esta formulación del sujeto, la identificación pasa a ser fundante del proceso originario y constitutivo de lo psíquico en un orden simbólico, como encarnación de un conjunto de significaciones imaginarias, entendiendo éstas como la solución fantasmal de las contradicciones reales (Ídem), y como parte central de la creación, la reproducción, y la crítica de los sentidos estructurantes de prácticas sociales.

Entendemos entonces la identificación, como un proceso de articulación de sutura, donde () Hay siempre demasiado o demasiado poco una sobre-determinación o una falta de, pero nunca una adecuación perfecta, una totalidad (Hall. 2003: 15). La identidad, como efecto de múltiples identificaciones imaginarias y simbólicas, tiene siempre lugar en la relación otro y con el Otro, con la alteridad imaginaria y simbólica, en el Discurso del Otro. Aquí es donde la distinción entre una identificación simbólica y una imaginaria se vuelve atingente, para entender los procesos de mutación en las identidades o la imposibilidad de las mismas.

Para decirlo simplemente con Slavoj Zizek (2000: 147), la identificación imaginaria es la identificación con la imagen con la que nos resultamos amables, con lo que nos gustaría ser; y la identificación simbólica es la identificación con el lugar desde el que nos observan, desde el que nos miramos de modo que nos resultamos amables, dignos de amor. La identificación se puede comportar así, como una falla, una debilidad, un sentimiento de culpa, o como una incesante búsqueda de completitud, de modo que cuando destacamos la falla podemos reafirmar la identificación, la que, por otra parte, está configurada y atravesada por una mirada en el Otro en la identificación imaginaria del sujeto consigo-mismo.

Este sujeto que es en sí mismo inexistente y que encuentra su complemento significante en el significante de la identificación (Miller 2005: 36), pareciese plasmarse radicalmente en estas dos dimensiones (imaginaria y simbólica), articulándose como una entidad constituida por un conjunto de posiciones de sujeto, las cuales

no pueden estar nunca totalmente fijadas en un sistema cerrado de diferencias; una entidad construida por una diversidad de discursos 
entre los cuales tiene que haber necesariamente relación, sino un movimiento constante de sobre-determinación y desplazamiento la identidad de tal sujeto múltiple y contradictorio, es por lo tanto, siempre contingente y precaria, fijada temporalmente en la interacción de las posiciones de sujeto dependiente de formas específicas de identificación (Mouffe 1993: 6-7).

En el marco de un contexto en transformación orgánica, que moviliza la producción y acumulación de sentidos, y revitaliza los procesos de identificación, una identidad que pretendiera continuar tal como es, mantenerse sin cambios, correría el riesgo de marginalización o de cristalización (Arfuch 2005: 34). Es desde allí, de donde proviene la imposibilidad de concreción plena y final de las identificaciones; ya que son objeto incesante de reconstitución y, como tales, están sometidas a la lógica volátil de la iterabilidad (Butler 2002: 159), en los mismos procesos de aceleración, cambio y reorganización histórica de la sociedad capitalista.

Lo particular es que las lógicas de dominación, las cuales transfieren la mirada del Otro hacia la constitución imaginaria y simbólica del sujeto en el proceso de identificación, se han movilizado desde los niveles de desintegración culturales, la aceleración de las lógicas disciplinares y control (Baker \& Hill 2003), hacia la erosión y mutabilidad gradual-limitada de las formas imaginarias de dominación, subordinación y explotación, en particular con respecto a la matriz del pensamiento neoliberal, (esto de forma desigual y en distintas esferas de colonización de la significación de lo social y la sociedad), es decir, en un decaimiento de su poder hegemónico, en tanto dispositivo de control social que supone una dominación de sentidos comunes y una operación subjetivante. Esto es, la presencia de códigos de significación dominantes que inciden en la construcción de sentidos por parte de los sectores subalternos (Retamozo 2006:8). El pensamiento neoliberal, como organizador simbólico interpretativo de la realidad, y como red de significantes explicativos y colmados de sentido compartido por los sujetos involucrados embebidos en la relación de dominación-poder comienza a redibujar sus alcances en el proceso de identificación del sujeto, en cuanto a su relación y como parte de la sociedad: su subjetividad, su condición de sujeto se desmarca de la identificación en el Otro.

Es en el plano de la construcción de estos sentidos comunes, como formas específicas de estructuración/estructurante, es donde están puestos los planos imaginarios y simbólicos de reorganización de los procesos de identificación, los cuales se van movilizando, desde los espacios de dominación, hacia la significación de la pérdida, y como reinterpretación de sentido en la falta sintómatica que desborda la disciplina. La identidad, pues está sujeta al tiempo, a la memoria, al memorizar, a los recuerdos, a la autobiografía, y estas cosas no están hechas sino en el lenguaje y palabras ${ }^{6}$, pero también en un presente que nombra y significa.

Así es como creemos que asistimos a un proceso más profundo que la crisis de la cultura como campo hegemónico de organización de senti- 
dos. A nuestro entender lo que se visualiza en la actualidad es más bien a la apertura de los campos de la subjetividad, como espacios diversos que permiten dar sentido, ya que al contener elementos acumulados para dar sentido socialmente, no a través de la identificación de códigos que reducirían la subjetividad a la cultura, como espacio simbólico nacional, etáreo, racial, etc., sino que como proceso que incorpora a los códigos acumulados, se puede advertir la creación de configuraciones subjetivas propias para la situación concreta de re-significación e identificación (De la Garza 2001: 95). Pero entonces: ¿Cuál es ésta situación concreta en la cual se resignifica hoy en día? Creemos que ésta situación concreta ésta atravesada por los cambios micro-físicos en las relaciones de poder, que llaman a renegociar permanente las condiciones del vínculo de sumisión, cooperación y compromiso en el proceso de (re)producción social, y que se expresan gráficamente en la crisis del modelo neoliberal como precarización de lo social (Castel 1997).

La reconfiguración del énfasis identitario, el cual sobreviene justamente en tiempos de crisis, desarraigo, inseguridad, vulnerabilidad e incertidumbre de presentes y futuros, pone en movimiento las señales de la sumisión (Bourdieu 2011: 31), como un juego, en donde los subordinados acuerdan permanentemente a sus superiores, y en donde se configuran las dimensiones discursivas y prácticas específicas de las estrategias de inversión simbólica (Ídem: 31). Estas últimas, son todas las acciones que apuntan a conservar y aumentar el capital de reconocimiento (en los diferentes sentidos), propiciando la reproducción de los esquemas de percepción y apreciación más favorables a sus propiedades y produciendo las acciones susceptibles de apreciación positiva según esas categorías (Ídem: 37).

Estas estrategias que atraviesan la pérdida que describen el mundo precario, y la precarización social, muestran ser elementos de producción de realidad que van atravesando el plano de la conformación simbólica e imaginaria dominante en los frágiles procesos de identificación, reconocimiento y conformación psíquica de los sujetos, como horizonte, reconocible aquí y allí en la superficie de una mundialización a ultranza, proceso el cual repercute en cada manifestación particular (Arfuch 2005: 13), incluida en ella, por su puesto, el trabajo como relación social.

En su constante forma de articular y modelar simbólicamente las relacionales de identidad, los dominados constituyen y reconstituyen sin cesar la relación de dominación o a la inversa, la relación objetiva de dominación impone los signos de sumisión (Bourdieu 2011: 31), lo que genera formas cada vez más específicas de dimensionar el problema de la identificación y la difuminación de sujetos, como también las formas de colaboración y cooperación en el proceso de explotación, y las distintas construcciones de identidad colectiva por parte de los explotados.

Éste problema se vuelve el núcleo de estudio del cambio en las relaciones de poder en el proceso de trabajo, así como de las formas de reflexividad, interpretaciones recíprocas y acciones de un (conjunto de) 
individuo(s) en un contexto de significación de la relación de trabajo/capital en la actualidad (Knights \& Willmott 1989; McCabe 2007).

\section{Identidad y trabajo. Subjetividad(es) laboral(es) precarias}

Los cambios desarrollados en el mundo del trabajo, con la emergencia de nuevos paradigmas o modelos productivos ${ }^{7}$, los cuales se posicionan de manera gradual como un nuevo tipo ideal de organizar la producción, adaptándose a las culturas locales, para desarrollarse con mayor rapidez y efectividad, han generando un importante impacto, modificando la relación entre cultura y trabajo. Esta relación, aparece interconectada por una determinación mutua, la cual se encuentra mediada por la interacción de los sujetos en el proceso de trabajo, que, a su vez, se inserta dentro del conjunto de la estructura global de las relaciones de poder entre los actores de la producción (Reygadas 2002: 117), como un proceso de ajuste y negociación permanente, entre, por una parte, el proceso de producción, reproducción y acumulación de capital, y por otra las disposiciones subjetivas y conformaciones de sentido de los hombres y mujeres que se introducen en éstas relaciones de subordinación ${ }^{8}$.

En este contexto, la cultura, como expresión de un espacio nacional homogéneo, deja de constituir un obstáculo para convertirse en una necesidad de un contexto económico globalizado y multicultural (Montaño 2000: 288). Por ello, en vez de la continuidad histórica de una tradición cultural nacional, más bien podríamos encontrarnos ante una irruptiva ruptura en la cadena cultural (Harvey 1989), frente a la posibilidad y contingencia de formación de nuevas estructuras sociales, y de nuevos espacios de la dominación referidos al movimiento y desenvolvimiento del Capital (Postone 1993).

Éste paradigma emergente finalmente es la consolidación de una transformación radical en la dimensión tecnológica, productiva, temporal y espacial, y de los modos de gestión empresarial, en su matriz disciplinar precedente, con lo que emerge un régimen de los plazos cortos que genera un modo de control abstracto y mercantil de la perpetuación de la competencia al interior de las empresas, entre sus trabajadores (Dörre 2009: 85), y fuera de ella, como un lugar coaccionado desde un no-lugar, ubicado en el miedo al desempleo, la desafiliación social y la permanente condición de vulnerabilidad. Aquí podemos ubicar una de las causas esenciales de la precarización laboral, como tendencia gradual de descomposición del empleo en su funcionalidad de mecanismo de integración estable.

El proceso de precarización cobra una dimensión estructural, al estar articulada con tres distintas corrientes por las que fluye el poder del capital: 
1) Una práctica de parte del poder político de desregular los mercados de trabajo y relaciones laborales acordes a la producción flexible, además de generar una estructura de desprotección y vulnerabilidad, que apunta a la polarización social;

2) Una práctica del poder del actor empresarial, en la modernización, reingeniería y reestructuración productiva y de las lógicas de organización del trabajo; y

3) Una práctica del poder económico, marcado por una tendencia internacional de financiarización de las economías, y la generación de una nueva división mundial del trabajo, con regimenes de trabajo intensivos basados en la sobreexplotación (Ross 2008).

En éste escenario la precariedad aparece, tanto como fenómeno económico-político proceso de neocolonización y avance del capitalismo financiero/neoliberal, y como un nuevo conjunto de disposiciones e imperativos de auto-reconocimiento en el trabajo, lo cual constituye la implantación de mecanismos normalizados de regulación, en el espacio de la producción referidos a interpelar al sujeto trabajador con su identidad y su actividad. La precariedad laboral se inscribe como un modo de dominación de nuevo cuño, basado en la institución de un estado generalizado y permanente de inseguridad que tiende a obligar a los trabajadores a la sumisión, a la aceptación de la explotación (Bourdieu 1999: 125-126).

Por ello, mientras estos procesos exigen de reordenamientos estructurales bruscos que trascienden el plano propiamente económico, introducen en el espacio del orden simbólico, alteraciones en las condiciones para la construcción de subjetividades, modificando las posibilidades/expectativas, interés, etc., de los sujetos sociales que disputan la hegemonía y la diversificación de formas de participación política, haciendo con ello atingente la noción de una identidad que vive en un proceso de imposibilidad de adecuación, que sufre la constante irrepresentabilidad en una posición que enfatiza la imcompletitud, el inacabamiento y por lo tanto, es más apta para dar cuenta de la creciente fragmentación contemporánea (Arfuch 2005: 24). Este modelamiento sistémico, propio de la lógica capitalista en la organización de los espacios de la producción social, impacta en los modelos de sujeción, en su matriz disciplinar, fuertemente coercitiva, punitiva y castigadora en los espacios de trabajo, mientras que en el mundo del desempleo como superpoblación relativa, cobraba una abismante fuerza de control, en el miedo a la desafiliación y desintegración social, que imbrica coactivamente las relaciones laborales en su presencia fantasmal-aterradora.

Pues bien, las relaciones sociales de producción no determinan las identidades y subjetividades mecánicamente, ni los sujetos son productos inmanentes de las contradicciones de las nuevas condiciones de acumulación del capital (O’Doherty \& Willmott 2001), por lo que la importancia del post-estructuralismo en el debate y análisis del proceso del trabajo (McCabe 2007), indica a la subjetividad como el centro de mediación en la relación de dominación, control y resistencia, sin ignorar la estructuración 
de relaciones sociales donde se desarrolla la asignación de sentido y la acción, en la cooperación y el compromiso (Buroway 1989), como vínculo de reproducción y producción en las relaciones de trabajo.

El debate acerca del proceso de trabajo en la actualidad, está marcado por las distintas vertientes de la precariedad, en la cual se reconfiguran los espacios de subjetivación (Ross 2008; Lee \& Kofman 2012). Las subjetividades emergentes presentan características inestables y contradictorias, en un mapa de condicionamientos que requieren de su mutabilidad permanente y de su identificación con una no-identificación. Richard Sennett (1998) señala que la experiencia del trabajo de las subjetividades actuales está cruzada por tres mecanismos: la relación con la dimensión temporal, la capacidad de renuncia y la relación con el talento. Esto parece ser parte de una cadena en la que el sujeto es conducido a:

1) observarse y reconocerse desde la conformación de una temporalidad inestable y cambiante, con la ausencia de contratos estables, la emergencia de contratos temporales y de población que no reúnen las condiciones objetivas/subjetivas necesarias para los requerimientos de un empleo formal;

2) una condición de renuncia a la seguridad, a cualquier tipo de cobertura, con la flexibilidad de despido, y cualquier forma de regulación/protección, con la correspondiente violación de los derechos sindicales y de negociación colectiva, por parte del empleador/a y del conjunto de la legislación laboral como parte de una estrategia de vulnerabilidad relacional (Castel 1991); y,

3) Una maximización del talento, como contra-tendencia adaptativa a la sobreexplotación auto-creativa en contra de la insuficiencia, relacionada a los subempleos, la individualización de la relación laboral, los salarios bajos y la autonomía encubierta.

En éste contexto la estructuración de acciones e identificaciones colectivas descansa aún así, en la existencia de tensiones derivadas de un cierto equilibrio de fuerzas en el sistema social y no en el predominio abierto del capital sobre el trabajo, ya que en la posibilidad de aquellos mismos campos de contradicción, negación, tensión y subordinación se constituyen las posibilidades de desenvolverse/expresarse en prácticas efectivas por parte de los agentes/actores sociales. Hay una imposibilidad de identificación (total) en el Otro. He ahí la base de la doble negatividad de cultura en la tensión entre producir y ser producido (Eagleton 2001: 16), lo cual de una u otra forma, va revirtiendo y modelando una redefinición orgánica de la construcción imaginaria del trabajo y el no-trabajo, en su dimensión abstracta y concreta, construcción la cual en la sociedad capitalista se constituye, de forma predominante, como asalariada, fetichizada y abstracta.

Es necesario en éste campo, el referido a la tensión entre la producción y reproducción de identidades precarias, considerar una gama de fenómenos, tales como la creciente incorporación de contingentes femeninos al mundo obrero, una sub-proletarización intensificada, presente en la ex- 
pansión del trabajo parcial, temporario, precario, subcontratado, tercerizado, que marca la sociedad dual en el capitalismo avanzado (Antúnez 2003: 43), pero que en países del capitalismo periférico cobra una expresión particular, referida a la precarización social, como parte constituyente y expresión de una crisis de la reproducción social.

Éstas dos áreas en tensión (producción-reproducción), se encuentran en directa oposición en la matriz del trabajo precario, al reconocer la mercantilización de los bienes de servicios, la protección social, la salud, la educación, etc., lo cual vuelven la precariedad laboral en un espacio central de articulación entre: a) los procesos estructurales de monetarización y burocratización, los cuales penetran en los ámbitos nucleares de la reproducción cultural, la integración social y la socialización (Habermas 2008: 384), como de la propia existencia/vida, y b) la crisis del rol del Estado en materia de protección, derechos y garantía social, es decir como foco del conflicto político-social por el bien-estar en las sociedades neoliberales.

De allí que identificar las coordenadas de emergencia y padecimiento de la dislocada clase trabajadora, como forma identificatoria (difusa) y con una nueva anatomía (compleja), constituyan parte importante para entender la dinámica de los procesos sociales, político, culturales y económicos que atraviesan la crisis y descomposición del proyecto neoliberal.

\section{Las identidades precarias subalternas ${ }^{9}$}

Como ya hemos señalado, las vertientes de la precarización han consolidado una nueva cartografía del mundo del (no) trabajo, con una mayor heterogenización, complejización y fragmentación de la-clase-que-vive-deltrabajo (Antúnez 2003: 87), a partir de la generación de una diversificada estructura productiva, en la cual se han instituido formas de trabajo atípico; una considerable emergencia del subempleo ${ }^{10}$, el desempleo ${ }^{11}$ y de nuevas relaciones entre tecnología e innovación productiva, por medio de una reestructuración de las relaciones laborales y la institucionalización de la precariedad laboral $^{12}$, articulando el nacimiento de nuevas identidades precarias y sujetas constantemente a las oscilaciones flexibles de los intereses del capital. En este segmento muchos/as trabajadores/as son abandonados por la afiliación sindical, por la negociación colectiva o por cualquier tipo de forma de articular sus demandas y necesidades en el trabajo ${ }^{13}$.

Este panorama que gráfica parcialmente una cuantificación de la precarización en el empleo, se vuelve en un elemento clave para entender la tendencia a la precarización social y un mapa de la cuestión en el modelamiento de las relaciones laborales. Pero claramente, para no caer en una cartografía estática y vacía, debemos reconocer, desde el plano de la identificación y la multiplicidad polisémica del trabajo que, en la flexibilidad e inseguridad del trabajo y del empleo, son subjetivados de diversas 
maneras por los trabajadores, tanto en la misma estructura social de clases de una formación social, como a nivel global (Lee y Kofman 2012); y a la vez aquello implica distintas consecuencias para la morfología de la cohesión social y para la activación política de los sujetos.

Si consideramos el caso de Chile en los dos últimos años, la organicidad de nuevas fuerzas sinérgicas colectivas han generado nuevos procesos de identificación, que desde el marco del discurso civil democrático, han ejercido prácticas indisciplinadas que muestran la mutabilidad y (des)ajustes del sustrato de dominación neoliberal, y que ponen en el centro de la política la movilización, los actores y los movimientos sociales. Su complejidad y nueva dinámica ha implicado la reorganización simbólica de un imaginario social radical (Castoriadis 1993), siendo allí donde se centra igualmente el rol de la contra-hegemonía, como sistematicidad objetivada de los procesos de subjetivación que recogen diversas expresiones de la precariedad ${ }^{14}$, a partir de la pauperización sistemática impuesta por el modelo neoliberal ${ }^{15}$.

En nuestro caso, que es el del trabajo, la precarización se asocia a formas específicas de subjetivación e integración social, en la relación sujeto-trabajo, donde, según la tipología desarrollada por Klaus Dörre (2009b: 48), se consideran nueve formas típicas de subjetivación que se asocian a tres zonas de cohesión social y que están referidas a un fenómeno que recorre la estructura social ${ }^{16}$, es decir, una precariedad discriminatoria, la cual asume un campo transversal en el plano de lo social, generando un proceso de ampliación de las bases de la precarización social a la clase de servicios y de cuellos-blancos ${ }^{17}$, lo cual implica nuevas formas de producción de lo colectivo y lo individual, especialmente en el sentido de la inscripción y introducción del goce y el deseo, y del interés-agencia (Spivak 2003), en el espacio de la sujeción.

Así es como la condición de precariedad repercute, no solo en modalidades de contratación a corto plazo, inestabilidad laboral, rotación de la mano de obra, o en una asimetría o paupérrima realidad en el nivel de ingresos, sino que también se articula como un campo complejo, en su morfología, para dar cuenta de aperturas, discontinuidades y fragmentos del espacio constitutivo de identidad(es) en/con el trabajo, y de movilización y cambios en la conformación de sentidos con respecto a la misma actividad social del trabajar, y el de ser-sujeto (social, político, etc.). En este sentido juega un papel fundamental la elaboración del otro junto con otros para elaborar, construir un nosotros frente a un ellos, evidentemente precario (Mora 2007: 16), una condición que constituya una identidad colectiva, en su dislocación y dispersión.

¿Es aquí donde entra en vigencia el concepto de clase social (Dörre 2012) para dar cuenta de la construcción de nuevas significaciones desde el espacio de los dispositivos disciplinares y en los espacios de resistencia y subversión de los mismos? Creemos que en el plano de las relaciones de antagonismo y subordinación, que van configurando 
re-codificando la realidad, existe un posicionamiento del sujeto con respecto a ella, una lectura y un discurso interpretativo que regenera los sentidos subordinados, y va consolidando una subjetividad de lo precario, de forma adaptativa y crítica, con una multiplicidad de significaciones negativas $^{18}$. En esta dirección es que los procesos de identificación del trabajo, al estar atravesados por la precariedad, se refieren a nuevas formas colectivas de organización e identidad en el trabajo, y es allí donde las clases, atravesadas, dislocadas y dispersadas, reconstituyen nuevos bloques políticos, generan alternativas imaginarias, simbólicas y prácticas contra aquellos sujetos/clases interesados en organizar su sometimiento; especialmente con respecto a todas vertientes de (la crisis de) la reproducción social, lo que hace de éstas resistencias, fenómenos de cooperación y movilización que trasciende la condición propiamente clasista, ya que a la vez reorganiza y modifica la misma posición/condición de clase, entendiendo por clase sociales relaciones de dependencia objetivadas entre subjetividades fragmentarias individuales y colectivas en proceso de formación (Mora 2007: 12).

De hecho, lo subalterno, es el centro de la cuestión al definir al precariado como sujeto político de identificación y acción colectiva, y allí es donde la clase social está dislocada y descompuesta. La condición de precariedad, en el caso de Chile, está asociada a un proceso de precarización social, como descomposición del proceso de reproducción social, ya que no tan sólo involucra las bases del trabajo, sino que está estrictamente articulada con los procesos de desregulación, privatización, liberalización, descomposición del régimen de bienestar y una política subsidiaria de parte del Estado, que termina por consagrar la desregulación y vulnerabilidad social estructural en la estrategia disciplinaria neoliberal. La clase trabajadora, como sujeto-nombrante, se inscribe en éste modelo de forma segmentada, con un proceso de violación sistemática de su memoria y con la redefinición estructural de sus contornos y composición, ya que al estar diferenciada en un heterogéneo collage-de-trabajadores, aún no logra transitar desde la inscripción en el Otro, a una constitución subjetiva e identificatoria en un-nosotros concreto.

Mientras que el precariado está en todas partes, y en ninguna, parece ser un eslogan global, la condición de su identidad está fijada profundamente en contextos y formaciones socio-históricas concretas. La condición subalterna que moviliza la precariedad está dada por la transversalidad de las relaciones de poder y dominación que reordenan el mapa de la cuestión disciplinaria y del control en un contexto histórico y un orden simbólico concreto. Es en ésta particular y concreta forma de sujeción, es donde se encuentra la contingencia de las “identidades precarias subalternas", como aquella identidad que se niega a inscribirse y ser inscrita en la marginalidad desde el margen, a reproducirse en ella y reproducir las relaciones de poder implícitas en el trabajo y el no-trabajo, y en el propio proceso de su constitución.

La inscripción de la identificación simbólica e imaginaria, la forma en que la falta se integra a una condición de sujeto, es la forma en que se 
moviliza la subalternidad, en la que creemos existe una carga simbólica política de una crítica a la falta, como protesta política y negación del trabajo en el contexto de una matriz neoliberal dominante (Antúnez 2005). Ésta situación re-instala la crítica a la explotación capitalista, en cuanto a las condiciones-de-la-explotación, más no de-la-explotación-en-sí-misma, y por ello se orienta a una narrativa crítica fundamentalmente de carácter cínica e irónica (Zizek 2000), en su dualización y distinción del trabajo (abstracto-concreto), lo que no impide que la precariedad movilice, en otros contextos y de forma desigual en la identidad precaria subalterna, una crítica negativa (unificada) del capitalismo, al ser entendida como parte de la estrategia global de reproducción del capital y como proceso diferenciado de las relaciones de poder, como la posición/condición de clase, que le subyacen.

En éste punto es donde volvemos a la importancia de las estrategias de inversión simbólica (Bourdieu 2011), como nueva fuente de reorganización de los sentidos de la relación de subordinación en el trabajo. Allí se encuentra la especificidad que puede diferenciar el espectro interclasista que parece constituir la precariedad como categoría (que moviliza la) política $^{19}$, ya que la precariedad impulsa a las fuerzas políticas a procesos de legitimación discursiva y de identificación (quizás imposible) con el nuevo sujeto de la precariedad, el cual en sus estrategias de inversión simbólica reconoce la asimétrica forma que asumen las relaciones laborales, como imbuidas de poder, así como un desplazamiento de sus sentidos de creencia y verdad en la misma relación de subordinación. Sin embargo, paradójicamente la precariedad descentra el terreno de la identidad de clases, y no hay punto de retorno/encuentro identificatorio para la condición precaria subalterna: un no-lugar de subjetivación que excede las clases sociales, y que más bien incita su reconstitución he integración dinámica de sentidos.

Así es como podemos apreciar que no tan sólo la dualidad entre institucionalidad laboral (como expresión de una cultura), y sus fracturas, en sus tendencias de conservación y mutabilidad hacia nuevas formas de significación y acción desde el espacio político, están mutando por medio de la precariedad y la emergencia de nuevas identidades críticas y subalternas, sino que los significados políticos en la falta y carencia, como gestores de la narrativa de la dignidad y lo digno, impregnan y se colocan también en el centro de la nueva cuestión social del siglo XXI (Castel 2007; Dörre 2009), en cuanto a nuevo acuerdo o desencuentro entre dominantes y dominados en la relación capital/trabajo, y en la (no) conformación de las clases sociales.

Este fenómeno parece constituir una tendencia a nivel global, el cual demarca el desarrollo del nuevo conflicto social de las próximas décadas en países como Chile, donde se alcanza una crítica crisis de la reproducción social, por medio de su abierta desigualdad social y falta de legitimación del régimen político y el modelo neoliberal. 


\section{Conclusiones}

En la actualidad, el contexto de precarización dinámico e inestable en el trabajo, se instituye como: a) una estrategia de reproducción de las relaciones de poder y subordinación; y como b) reconfiguración de los focos, expresiones y formas de resistencia que asume hoy la dislocada clase trabajadora. Este fenómeno, el cual es entendido en la matriz de la clase trabajadora latinoamericana (con todas sus respectivas diferencias nacionales, sectoriales, generacionales, etc.) de forma claramente contradictoria y sintomática, comienza a impulsar procesos de subjetivación colectivos que asumen la precariedad, la informalidad, el no-trabajo, etc., como nuevas formas de identificación, las cuales, lejos de constituir y reproducir formas de naturalización y disciplinamiento en el trabajo, se encuentran en la tensión contradictoria que reúne el agotamiento representacional del trabajo como estático, perpetuo e inmodificable, y la condición de posibilidad de la generación de procesos de colectivización y construcción de identidad(es) subalternas en resistencia al proceso de control (total) en el trabajo.

Con respecto a dar cuenta de las formas de resistencia en el caso de Chile, creemos necesario adentrar la investigación social en el reconocimiento y exploración de: 1) el papel del llamado sindicalismo de base, las organizaciones de subcontratados, el de los colectivos de trabajadores, el de la ocupación de fábricas, y principalmente las formas de resistencia inscritas en la ilegalidad etc., como expresiones que se desmarcan del ordenamiento de una Otredad en el significar la relación trabajo-capital, y reinscriben los actos de resistencia e insubordinación en el trabajo; y 2) las formas y mecanismos adaptativos de resistencia que redirigen el sindicalismo hacia una heterogeneidad de organizaciones que buscan aglutinar a la (heterogénea) clase trabajadora, como los comités paritarios, grupos informales, colectivos de trabajadores, etc., y que se expanden a la clase de servicio, y las ponen en comunicación, por medio de la precariedad, con los demás actores y movimientos sociales en una confluencia de necesidades, proyectos, demandas y expectativas multisectoriales altamente complejas, así como con una particular relación con los partidos políticos y el sistema político.

En medio de la diatriba de, por una parte la carga atomizante y fragmentaria de la precariedad y la flexibilidad laboral, y por otra, su potencial exacerbación sinérgica de una identidad colectiva del explotado y del marginado (subempleado y desempleado), se encuentra el diálogo sobre el potencial inhibidor de las formas colectivas de organización que ambos fenómenos representan, y la potencia carga significante en la lógica de sobreexplotación, que reconfigura la forma de auto-concebirse como precario, e identificarse-a-sí-mismo (y a un otro) como igualmente explotado, y por lo tanto, de dar forma la (in)estabilidad de las relaciones de poder al interior del trabajo, y las formas de praxis socio-política que asumen los actores del trabajo. 
A la vez, parece contradictorio que éstas identidades precarias subalternas, las cuales alientan éste proceso de cuestionamiento (social) y de crisis (de la política), se encuentran profundamente marcadas por la ausencia y falta de constitución en un sujeto de poder, un sujeto con proyectos de conciencia de clase, y de transformación de la conciencia de clase o con la tenencia de una voz propia, como hablante político con nombre propio (Spivak 2003: 313), ya que ésta situación lo expone a la manipulación ideológica de fagocitación de la condición subalterna de la precariedad en el sistema político ${ }^{20}$.

Los discursos sobre el cambio cultural laboral, comienzan a combinar e incluir en sus estrategias discursivas de legitimación, las demandas sociales a cambios estructurales en orden a la precariedad. Lo cierto es que la falta de nombre propio ha dejado un vacío epistémico-representacional a conquistar en el plano de la ideología, del conocimiento y la política (un sujeto perdido), lo cual constituye hoy parte de la sobrecarga de significados dominantes que recorre imaginariamente el plano del discurso y promueve la identificación sumisa (la fe) en el sistema de partidos y la democracia. Las relaciones de poder/subordinación que les son propias a una economía capitalista como la chilena están en juego, y parecen someterse a un serio ajuste de su matriz de (re)producción.

Resaltamos que la temática expuesta, muestra indirectamente que la heterogeneización y precarización del trabajo sienta a la vez, no tan sólo nuevas coordenadas para entender el mundo del trabajo hoy en día, sino que reorganiza en parte la pretensión del trabajo como categoría central en la teoría social, en cuanto a alcanzar un análisis y concepción de la sociedad que articule el metabolismo de las sociedades moderno-periféricas.

Ésta temática renueva las discusiones sobre el debate identitario en el trabajo ${ }^{21}$, he impulsa un escenario de reconstrucción y reunificación, solidaria, dinámica de las particularidades, divergencias y diversidades, que no proviene de un incluir a través de la domesticación y la subordinación (Butler. 2001: 113), a la hora de establecer la articulación con otras fuerzas en pugna, desde algún lugar de una universalidad (inter) nacional abstracta, sino que a partir del nuevo campo concreto de sujeciones, manteniendo el conflicto de modo políticamente productivo, desde su propia temporalidad limitada, como lo requiere hoy el desafío del fragmentado y ampliado mundo del (no)trabajo, y las precarias formas de identificación entre trabajadores y trabajadoras en las distintas manifestaciones de las condiciones de la explotación flexible y precarias. 


\section{Notas}

${ }^{1}$ Este artículo es parte de los avances de la investigación Doctoral Transformaciones y metamorfosis del trabajo en Chile (1975-2010) bajo la tutela de Klaus Dörre. Universidad Friedrich Schiller. Jena, Alemania, como Becario Conicyt 2010-2014

${ }^{2}$ La precarización ahora es, aún menos que antes, un problema de grupos sociales marginales. Más bien, asume un carácter discriminatorio en cuanto se extiende al parecer paradojalmente a través de todas las zonas de cohesión social

${ }^{3}$ Para una polémica entre Eagleton y Spivak recomendamos la lectura de Wright (2002), en referencia especialmente a la crítica de la teoría marxista al postcolonialismo y viceversa, desde el espacio y el lugar.

${ }^{4}$ Para una revisión de este tema recomendamos la lectura de Eagleton (2001: 11-54).

${ }^{5}$ De manera tal que no es posible pensar la cultura como una sumatoria aleatoria de significados que se encuentran en un momento determinado. (Retamozzo 2005: 12).

${ }^{6}$ el point de capiton es, antes bien, la palabra que, en tanto palabra, en el nivel del significante, unifica un campo determinado, constituye su identidad: es, por así decirlo, la palabra a la que las cosas se refieren reconociendo su unidad. (Zizek 2000: 136)

${ }^{7}$ Históricamente, los mayores cambios de paradigma han sido el resultado de una activa y prolongada búsqueda emprendida cuando se percibe que se han encontrado ciertos límites en la situación anterior, pero no siempre la búsqueda parte de una perfecta información, sino que actúa mediante sistemas o procesos de prueba y error. Ahora bien, cuando se adoptan de manera generalizada las nuevas tecnologías, el resultado del cambio es generalmente irreversible.

${ }^{8}$ Es claro que lejos de hacer una alegoría de la subordinación, entendemos el carácter relacional del trabajo, ya que éste no es reconocible por la existencia de una coacción, sino por la naturaleza y el alcance de ésta. Dicho en otras palabras: trabajar no es la consecuencia de una mera subordinación, sino aquello que está en juego en una relación específica. Para participar en el intercambio perpetuo de bienes y servicios sociales, el trabajador se ve obligado a consumir en el trabajo un cierto tiempo de su existencia, tiempo obtenido y apreciado por procedimientos variables según los sistemas (Rolle 2010: 121).

${ }^{9}$ Hacemos aquí una mención importante al trabajo de Fundación SOL, la cual es una institución sin fines de lucro que realiza investigación, estudios, talleres y asesorías sobre el mundo del trabajo en Chile, como parte de un enfoque crítico de desarrollo, y que ha puesto un conjunto de análisis y datos para la cuantificación de la precariedad en el mercado de trabajo en Chile, los cuales utilizamos en el presente apartado con el fin de exponer nuestro análisis en relación a la cuantificación y fenómenos identitarios de la precariedad. Trabajaremos con los resultados de su Minuta Estadística No. 28 del trimestre septiembre-noviembre de 2012. disponible on-line en: http:/www.fundacionsol.cl/wp-content/uploads/2013/ 01/Minuta-Empleo-SON-12.pdf

${ }^{10} \mathrm{El}$ subempleo ha llegado a 696 mil personas (9 \%) que trabajan jornada parcial y quieren trabajar tiempo completo, pero no encuentran este tipo de empleo. Estos empleos que no 
cuentan con ningún de tipo de protección y seguridad, (Fundación SOL 2012).

${ }^{11}$ La Tasa de Desempleo Integral, que incluye su cálculo el desempleo abierto u oficial declarado por el gobierno (6,2\%) lo que equivale a 506.815 trabajadores/as; más el desempleo oculto y el desempleo equivalente por subempleo, alcanza un $11,5 \%$, lo que equivale a 948.322 desocupados de una población ocupada de 7.674.996 (Fundación SOL 2012).

${ }^{12}$ Sólo un 40,5\% (3.108.373 ocupados) de las personas registradas como ocupadas en la Nueva Encuesta Nacional de Empleo correspondientes al trimestre septiembre-noviembre 2012 presentan un empleo protegido, vale decir, con contrato escrito, indefinido, liquidación.

${ }^{13}$ La Fundación SOL (2012: 21) define la categoría de trabajador Subordinado Independiente, como los asalariados que no tienen liquidación de sueldo, vale decir, deben enfrentar todas las normas y sistemas de control de un trabajo dependiente, pero no cuentan con el sistema de protección de derechos laborales que caracteriza a un asalariado convencional. En el trimestre septiembre-noviembre 2012, esta categoría alcanzó un 18,7\% del empleo asalariado (privado, público y servicio doméstico), lo que equivale a 1.065.156 personas y la mayoría de ellas, ni siquiera entregan una boleta de honorarios.

${ }^{14}$ Aquí podemos asociar, a modo de ejemplo, el movimiento estudiantil (2011-2012), como respuesta a un acelerado proceso de mercantilización, privatización, desigualdad social y endeudamiento con respecto al acceso a la educación universitaria, lo cual ponía en entre dicho formas de ascenso y movilidad social; condiciones de trabajo precarias y una significación del trabajo profesional (debido a la relación entre empleo profesional, status y clase de servicios); como demanda de garantías sociales para la reproducción social en el bien-estar, con la conceptualización de la educación como un derecho social; y como apertura a sujetos silenciados socialmente (los jóvenes) y a narrativas/ expresiones y sentidos irruptivos.

${ }^{15}$ Es de notar que sólo 54,4\% de los trabajos asalariados están protegidos.

${ }^{16}$ Por temas de espacio, y los avances de nuestra investigación, no nos proponemos en este texto presentar extendidamente esta tipología, sino más bien clarificar la precariedad como fenómeno transversal a las zonas de cohesión social, lo cual lo vuelve un fenómeno interclasista.

${ }^{17}$ La cifra del subempleo profesional llega a 471 mil, lo que representa al 6\% del total de ocupados, siendo los sectores económicos de Intermediación Financiera (8,2\%), el sector público (10\%) y Minería (10\%) los que proporcionalmente más subempleados profesionales contienen (Páez 2011).

${ }^{18}$ Algo así como un remplazo, al contestarlo tanto como una apropiación un suplemento de algo que es artificial para comenzar condiciones económicas que separan su modo de vida (Spivak 2003: 312).

${ }^{19}$ Por ello aquí la importancia del análisis propuesto por Dörre (2009) que permite diferenciar las perspectivas y expectativas sociales con respecto a las relaciones laborales y el proceso de trabajo, por parte de los sujetos que constituyen una relación precaria.

${ }^{20}$ Creemos que esta situación se vuelve problemática en un clima de silenciamiento estruc- 
tural que prefigura las bases para una nueva solución patronímica con respecto al poder estatal.

${ }^{21}$ Hemos descartado dirigirnos en la direccionalidad de un postmodernismo miope que exalta el fetichismo de la(s) diversidad(es), ni la de un marxismo dogmático (en su peor versión estructuralista y determinista), ciego frente a la creatividad y la vitalidad de, por ejemplo, los nuevos movimientos sociales. 


\section{Bibliografía}

Antúnez, R. (2003), ¿Adiós al Trabajo? Ensayo sobre metamorfosis del trabajo y el rol central del trabajo, Ed. Herramienta, Buenos Aires.

Ídem (2005), Los Sentidos del Trabajo. Ensayo sobre la afirmación y negación del trabajo, Ed. Herramienta, Buenos Aires.

Arceo, Enrique (2005), “El impacto de la globalización en la periferia y las nuevas y viejas formas de la dependencia en América Latina”, Cuadernos del Cendes año 22, № 60, Tercera época septiembre-diciembre: 25-61.

Arfuch, Leonor (2005), “Problemáticas de la Identidad”. En Identidades, sujetos y subjetividades. (Comp. Leonor Arfuch). Prometeo Libros. Buenos Aires: 2144.

Baker, Isabelle \& Stephan Gill (2003), Power, production, and social reproduction: human in/security in the global political economy, Houndmills, Basingstoke, Hampshire; Palgrave Macmillan, New York.

Bourdieu, Pierre (1999), Contrafuegos, Anagrama, Barcelona, España.

Ibíd. (2011), Las estrategias de la reproducción social, Siglo XXI editores, Buenos Aires.

Boyer, R. (2007), Crisis y Regímenes de Crecimiento. Una introducción a la teoría de la regulación, Miño y Dávila, Buenos Aires.

Burawoy, M. (1979), Manufacturing consent: changes in the labor process under monopoly capitalism, University of Chicago Press, Chicago.

Butler, J. (2001) “El marxismo y lo meramente cultural”, New Left Review $\mathrm{N}^{\mathrm{o}}$ 2: $109-121$.

Ídem (2002) Cuerpos que importan. Sobre los límites materiales y discursivos del sexo, Paidós, Buenos Aires.

Castel, Robert (1991), "Los desafilados: precariedad del trabajo y vulnerabilidad relacional”. Revista Topía, año I, no. 3, noviembre: 28-35)

Ídem (1997), La metamorfosis social de la cuestión social. Una crónica del salariado. Ed. Paidos Ibérica, S.A. España.

Ídem (2007), “Los desafíos de las mutaciones sociales, políticas y económicas del siglo XXI”. Temas y Debates. $N^{0} 13$. Conferencia en la Universidad de Rosario. 19/09/2006.

Castoriadis, C. (1993), La institución imaginaria de la Sociedad, Tusquets Editores, 2 Vol, Buenos Aires. 
Cruces, Guillermo \& Andrés Ham (2010), La flexibilidad laboral en América Latina: las reformas pasadas y las perspectivas futuras. CEPAL. Colección Documentos de Proyectos. Naciones Unidas. Santiago, Chile.

De la Garza, Enrique (2001), “Subjetividad, cultura y estructura”, Revista Iztapalapa 50. Enero-junio: 83-104.

Ídem (2001b), “Problemas clásicos y actuales de la crisis del trabajo”, en El trabajo del futuro. El futuro del trabajo. Enrique de la Garza Toledo \& Julio César Neffa (comps.) Consejo Latinoamericano de Ciencias Sociales, Buenos Aires: 11-31.

De La Garza, Enrique y Julio César Neffa (2010), “Modelos económicos, modelo productivo y estrategias de ganancia: conceptos y problematización”, en Trabajo y modelos productivos en América Latina: Argentina, Brasil, Colombia, México, y Venezuela luego de las crisis del modo de desarrollo neoliberal, E. De la Garza \& J. Neffa (coord.) Consejo Latinoamericano de Ciencias Sociales, Buenos Aires: 15-47.

Dörre, Klaus (2009), "La Precariedad ¿Centro cuestión social del siglo XXI?”. Revista Actuel Marx Intervenciones. $\mathrm{N}^{\circ}$ 8. La pesantez de la vida cotidiana. LOM ediciones: 79108.

Ídem (2009b), Prekarität in Finazmarket-Kapitalismus. En Prekatität, Abstieg, Ausfrenzung. Die soziale Frage am Beginn des 21. Jahrhunderts, Klaus Dörre y Robert Castel compiladores. Campus: 35 64, Alemania.

Ídem (2010), “Social Class in the Process of Capitalism Landnahme. On the relevance of secondary explotation”, Socialist Studies/Études socialistes 6(2): 43-74.

Ídem (2012), “Abwertung, die aus der Mitte kommt. Prekarität als fatales Wettbewerbssystem”, in Eine Frage der Klasse? Deutschlands Mitte zwischen Abstiegsangst und dem Tritt nach unten. Heinrich Böll-Stiftung Brandenburg, S. 18-43.

Eagleton, Terry (2001), La idea de cultura. Una mirada política sobre los conflictos culturales, Paidós. Barcelona, Cataluña.

Fundación SOL (2012) Minuta de Empleo N² 28. Septiembre - Noviembre 2012. [on line] http://www.fundacionsol.cl/wp-content/uploads/2013/01/ Minuta-Empleo-SON-12.pdf

Habermas, Jürgen (2008), El discurso filosófico de la modernidad, Katz editores, Buenos Aires.

Hall, Stuart, (2003), Introducción: “¿Quién necesita identidad?”, en Cuestiones de identidad cultural. S. Hall y Paul Du Gay (comps.) Amorrortu, Buenos Aires. 
Harvey, D. (1989), The Condition of Postmoderrnity. An inquiry into the origins of cultural change. Oxford, Cambrigde.

Ídem, (2007), Breve Historia del Neoliberalismo, Akal, Madrid.

Julián, Dasten (2012), Dispositivos de disciplinamiento en el Trabajo. Relaciones laborales y subjetividad(es) en el Trabajo en Chile. Revista Si Somos Americanos. Vol. 12. $\mathrm{N}^{\circ} 2$.

Knigths, David \& Hugh Willmott, (1989), "Power at power: Subjetivity at Work: From Degradation to Subjugation in Social Relations”, Sociology 23(4): 535-558.

Lee, Ching Kwan \& Yelizavetta Kofman, (2012), “The politicis of Precarity: Vievs Beyond the United States”. Work and Ocuppations 39 (4): 388-408.

McCabe, Darren (2007), “Individualization at Work? Subjetivity, Teamworking and Anti-Unionism”. Jounal Organization, Vol. 14(2): 243 266.

Miller, J. A. (2005), El Otro que no existe y sus comités de ética. Paidos. Buenos Aires.

Montaño, Luis (2000), “La dimensión cultural en las organizaciones”. En Tratado Latinoamericano de Sociología del Trabajo. Enrique de la Garza (coord.). Fondo de Cultura Económica. Pp. 285 311, México.

Mora, Enrico (2007), “Las dimensiones fragmentaria y performativa de las subjetividades de clase”, Revista. Universitas Psychologica, Vol. 6. N. 001: 11-25. Bogotá, Colombia.

Mouffe, Chantal. (1993) “Feminismo, ciudadanía y democracia radical”. Revista Debate Feminista. Vol. 4: 3-22.

ODoherty, Damian \& Hugh Willmott (2001), "Debating Labour Process Theory: The Issues of Subjectivity and the relevance of Poststructuralism”, Sociology, Vol. 35 (22): 457476.

Páez, Alexander (2011), “El papel del subempleo profesional en la recuperación del empleo”. Diario El ciudadano [on-line]. (03/10/2011) Disponible en: http://www.elciudadano.cl/2011/10/03/41777/el-papel-delsubempleo-profesional-en-la-recuperacion-del-empleo/

Postone, M. (1993), Time, labor, and social domination: a reinterpretation of Marx's critical theory. Cambridge England; Cambridge University Press, New York.

Retamozo, Martín (2005) “Trabajo, subjetividad y acción: Desempleo, sentidos y acción colectiva”, $7^{\circ}$ Congreso Nacional de Estudios del Trabajo, 
Asociación Argentina de Especialistas en Estudios del Trabajo (ASET), Buenos Aires.

Ídem (2006), “Subjetividad, desempleo y acción: el movimiento de desocupados en Argentina”, V Congreso Nacional de AMET, Trabajo y Reestructuración: los retos del próximo siglo, Yucatán.

Reygadas, Luis (2002), “Producción simbólica y producción material: Metáforas y conceptos en torno a la cultura del trabajo”, Nueva Antropología, Vol. XVIIII (60): 101-119.

Ross, Andrew (2008), “The new Geography of Work: Power to the Precarious?”, Theory, Culture \& Society, Vol. 25(78): 3149.

Sennett, R. (1998), La corrosión del carácter, Anagrama, Barcelona, España.

Spivak, G. C. (2003), “¿Puede hablar el subalterno?”, Revista Colombiana de Antropología. Vol. 39, enero-diciembre: 297 - 364.

Vallejo, A. (1987), Vocabulario Lacaniano. Helguero editores. Buenos Aires, Argentina.

Wrigth, Colin (2002), "Centrifugal Logics: Eagleton and Spivak on the Place of Place in postcolonial Theory”, Culture, Theory and Critique, 43:1, 6782.

Zizek, S. (2000), El sublime Objeto de la Ideología, Siglo XXI, España.

Recibido: 11.06.2012

Aceptado: 10.04.2013 